\title{
Estado e industrialização pesada no Brasil: uma discussão teórica sobre o Plano de Metas $(1956$ - 1961)
}

\author{
Acson Gusmão Franca
}

Resumo: O presente artigo se propõe a realizar um estudo sobre o Plano de Metas e sua relação com a industrialização pesada no Brasil no período 1956 - 1961, tendo como orientação mais geral a atuação do Estado brasileiro na elaboração e execução desse plano, por meio do planejamento econômico. Para tanto, primeiramente será apresentado o plano e suas metas setoriais, os problemas enfrentados pelo Estado para executá-lo e as alternativas encontradas para superá-los. Em seguida, serão exibidos e discutidos os resultados alcançados, bem como os impactos desses planos na indústria e na economia brasileiras. Em suma, os resultados auferidos com este estudo, além de enaltecerem a importância do Plano de Metas enquanto primeira estratégia de desenvolvimento colocada em prática no Brasil, também revelam as vicissitudes criadas pelo ingresso do capital estrangeiro na economia brasileira nesse ínterim.

Palavras-chave: Crise. Estado. Industrialização pesada. Planejamento econômico. Plano de Metas.

Abstract: The present article proposes do a study about the Plano de Metas and its relation with the development of heavy industrialization in Brazil in the period 1956 - 1961, having as more general orientation of the Brazilian State in the elaboration and execution of this plan through economic planning. To do so, firstly will be presented the plan with its sectoral goals, the problems faced by the State to execute it and the alternatives found to overcome them. Then, the results achieved by said plan will be presented and discussed, as well as the impacts they have caused in the industry and in the brazilian economy as a whole. In short, the results obtained with this study, besides praising the importance of the Plano de Metas as the first development strategy put into practice in Brazil, also reveal the vicissitudes created by the entry of foreign capital into the brazilian economy in the meantime.

Keywords: Crisis. State. Heavy Industrialization. Economic Planning. Plano de Metas.

\section{Introdução}

A chegada de Juscelino Kubitschek trouxe, além de novas perspectivas para o futuro do Brasil, o desejo do então presidente de gerir uma política de desenvolvimento econômico que conseguisse acelerar o processo de crescimento, de modo a superar o estado de atraso e, consequentemente, alcançar a prosperidade mediante a implantação da indústria pesada ${ }^{2}$. Entretanto, diante da escassez de

\footnotetext{
1 Graduado em Ciências Econômicas pela Universidade Federal dos Vales do Jequitinhonha e Mucuri (UFVJM), com Mestrado em andamento no Programa de Pós Graduação em Desenvolvimento Econômico do Instituto de Economia da Universidade Estadual de Campinas (UNICAMP). E-mail: acson_franca@yahoo.com.br.

${ }^{2}$ Segundo a fala de JK contida em CARDOSO, M.L. Ideologia do desenvolvimento. Brasil: JK/ JQ. Rio de Janeiro: Paz e Terra, 1978, p.77: “Acentua-se a fase de transição de nossa economia, do estágio predominantemente agropecuário, para o estágio da industrialização intensiva, quando já se impõe evoluir da prática, quase exclusiva, das simples indústrias de transformação para as indústrias de base. Pretende-se ampliar, estimular e fundar as indústrias de que o Brasil necessita para sua completa e verdadeira libertação econômica: a indústria siderúrgica, a metalúrgica, a produção de cimento, a fabricação de fertilizantes, a mecânica pesada, e a química de base entre outras".
}

Página 39 Caderno de Ciências Sociais Aplicadas, Vitória da Conquista/BA, vol. 16, n 27, ano 16, p. 39-57, jan/jun 2019. 
recursos da economia no período, a execução dessa política só seria possível pela participação direta do Estado, via planejamento econômico, considerado indispensável na definição de prioridades, alocação de recursos, bem como na criação de determinados incentivos orientados a tal finalidade proposta naquele período ${ }^{3}$.

Nesse sentido, no intuito de apresentar as primeiras ideias do seu programa de governo, Juscelino Kubitschek, após viajar por todo o Brasil, elaborou em 1955 um documento intitulado Diretrizes Gerais do Plano Nacional de Desenvolvimento. Nesse documento, foram determinadas uma série de objetivos (metas) e as condições necessárias para que a iniciativa privada brasileira, com o auxílio do capital estrangeiro, e a ação governamental pudessem realizar o progresso e a emancipação econômica do Brasil nos cinco anos vindouros. Em outras palavras, a ideia do Plano Nacional de Desenvolvimento era "acelerar o processo de formação de riqueza, aumentando a produtividade dos investimentos existentes e aplicando novos em atividades reprodutivas” (OLIVEIRA, 1955, p.25).

Os objetivos propostos nesse plano se consubstanciaram posteriormente no Plano de Metas, núcleo básico da política econômica do governo de Juscelino Kubitschek e objeto de estudo do presente trabalho. Nesse sentido, este trabalho, que se destina a realizar um estudo acerca do Plano de Metas (1956- 1961), executado no governo de Juscelino Kubitschek, foi dividido em duas partes complementares. A primeira contemplará a composição do Plano de Metas e as questões relacionadas à sua implementação, tendo como base uma releitura do documento oficial do Conselho de Desenvolvimento Nacional, que lançou o plano, e outras bibliografias específicas. A segunda e última parte do texto apresentará e discutirá os resultados alcançados pelo Plano de Metas no que se refere ao processo de industrialização da economia brasileira, bem como as vicissitudes criadas devido à sua execução ao longo desse período, que vai de meados da década de 1950 até o início da década de 1960.

\footnotetext{
3 OLIVEIRA, J. K. Diretrizes gerais do Plano Nacional de Desenvolvimento. Oscar Nicolau, Belo Horizonte - MG, 1955, p.25, ressaltou o papel do Estado no esforço do planejamento econômico para a realização da política desenvolvimentista por ele proposta: "Essa assistência constante e eficaz que o Estado deve prestar ao empresário e ao trabalhador nacionais, se quiser, ao mesmo tempo promover o desenvolvimento econômico do País e incentivar o regime da iniciativa privada, tem, de se traduzir primeiramente por um esforço de planejamento, no sentido de orientar a economia brasileira para a sua expansão. [...] A ação orientadora do Estado deve procurar eliminar as influencias nocivas dos ciclos de prosperidade e depressão, que ocasionam imensos desperdícios de esforços; deve adotar medidas que facilitem as transformações estruturais da economia, evitando que essas se processem através das crises que caracterizam o desenvolvimento espontâneo, e deve incrementar a capacidade de poupança, - para só citar alguns setores em que é essencial a sua presença".
}

Página 40 Caderno de Ciências Sociais Aplicadas, Vitória da Conquista/BA, vol. 16, n 27, ano 16, p. 39-57, jan/jun 2019. 


\section{O Plano de Metas (1956-1961)}

O Plano de Metas consistiu em um conjunto de trinta metas setoriais, orientadas para dar continuidade ao processo de substituição das importações e superar os principais pontos de estrangulamento que impediam a expansão industrial da economia brasileira, tais como os setores de infraestrutura e insumos básicos (LESSA, 1983) ${ }^{4}$. Para tanto, exibia um conjunto dinâmico e progressivo de obras e novos empreendimentos a serem realizados nos setores de energia, transportes, alimentação, indústria de base e educação, com conclusão prevista de cinco a dez anos ${ }^{5}$, como mostra o Quadro 1.

Quadro 1: Plano de Metas (1956 - 1961): metas propostas e resultados esperados

\begin{tabular}{|c|c|c|c|}
\hline SETOR & $\begin{array}{l}\text { INVESTIMENTO } \\
\text { PLANEJADO (\%) }\end{array}$ & META & RESULTADOS ESPERADOS \\
\hline \multirow{4}{*}{ Energia } & \multirow{4}{*}{$43,40 \%$} & 1 - Energia Elétrica & $\begin{array}{l}\text { Elevação da potência instalada de } \\
3.000 .000 \mathrm{kw} \text { para } 5.000 .000 \mathrm{kw} \text { até } 1960 \\
\text { e ataque de obras que possibilitarão o } \\
\text { aumento para } 8.000 .000 \mathrm{kw} \text { em } 1965 .\end{array}$ \\
\hline & & 2 -Energia Nuclear & $\begin{array}{l}\text { Instalação de uma central atômica } \\
\text { pioneira de } 10.000 \mathrm{kw} \text { e expansão da } \\
\text { metalurgia dos minerais atômicos. }\end{array}$ \\
\hline & & 3 - Carvão Mineral & $\begin{array}{lll}\text { Aumento da produção de carvão de } \\
2.000 .000 \text { para } 3.000 .000 & \text { de } \\
\text { toneladas/ano com ampliação } & \text { da } \\
\text { utilização "in loco" para fins termelétricos } \\
\text { dos rejeitos e tipos inferiores }\end{array}$ \\
\hline & & $\begin{array}{l}4 \text { - Petróleo } \\
\text { (Produção) }\end{array}$ & $\begin{array}{l}\text { Aumento da produção de petróleo de } 6 \text {. } \\
800 \text { barris em fins de } 1955 \text { para } 100.000 \\
\text { barris de média de produção diária em } \\
\text { fins de } 1960 \text {. }\end{array}$ \\
\hline
\end{tabular}

${ }^{4}$ É importante ressaltar que a elaboração desse plano resultou de uma série de estudos e diagnósticos realizados por diferentes missões e comissões econômicas, como a Missão Abink, a Comissão Mista Brasil Estados - Unidos e a Missão BNDE/CEPAL, ambas criadas no governo de Getúlio Vargas para detectar os principais problemas brasileiros e consequentemente fazer projeções futuras. OLIVEIRA, JK. A Marcha para o Amanhecer. São Paulo: Bestseller - Importadora de Livros S.A, 1962, resume a importância do Plano de Metas para o Brasil: "Em entrevista coletiva à imprensa europeia, resumi o sentido do Programa de Metas: revigorar nossa democracia por meio do desenvolvimento econômico e social; fomentar o interesse do povo brasileiro pela solução de seus problemas básicos; dar prioridade à expansão dos suprimentos de energia elétrica; aumentar a produção nacional de petróleo e respeitar as leis que criaram a Petrobrás; estimular a imigração qualificada, mormente ingresso de técnicos e especialistas; solicitar ao Congresso meios para a transferência da capital brasileira para o interior do país; promover a maior cooperação brasileira com os países da América do Sul; incrementar o intercâmbio cultural franco-brasileiro, principalmente no que tangia às atividades artísticas e universitárias; desenvolver a nossa indústria cinematográfica."

${ }^{5}$ De acordo com Oliveira (1955, p.43): “A definição de cada meta ou grupo de metas implica uma análise dos métodos a serem preferidos e da política a ser seguida para que possam elas ser atingidas. Dessa forma, existirão metas quantitativas de produção, ao lado de metas de serviços e metas de organização. Existirão definições de políticas específicas para certos setores econômicos ou sociais".

Página 41 Caderno de Ciências Sociais Aplicadas, Vitória da Conquista/BA, vol. 16, n 27, ano 16, p. 39-57, jan/jun 2019. 


\section{- Cadernos de Ciênclas SOCIAIS APLICADAS}

\begin{tabular}{|c|c|c|c|}
\hline & & $\begin{array}{l}5 \text { - Petróleo } \\
\text { (Refinação) }\end{array}$ & $\begin{array}{l}\text { Aumento da capacidade de refinação de } \\
130.000 \text { barris diários em } 1955 \text { para } \\
330.000 \text { barris diários em fins de } 1960 \text {. }\end{array}$ \\
\hline \multirow{7}{*}{ TRANSPORTES } & \multirow{7}{*}{$29,60 \%$} & $\begin{array}{l}6 \text {-Ferrovias } \\
\text { (Reaparelhamento) }\end{array}$ & $\begin{array}{l}\text { Reaparelhamento das ferrovias, com } \\
\text { aquisição de } 11.000 \text { vagões, } 90 \text { carros de } \\
\text { passageiros, } 420 \text { locomotivas modernas e } \\
850.000 \text { t de trilhos novos. }\end{array}$ \\
\hline & & $\begin{array}{l}7 \text { - Ferrovias } \\
\text { (Construção) }\end{array}$ & $\begin{array}{l}\text { Construção de } 2.100 \mathrm{~km} \text { de novas } \\
\text { ferrovias e } 280 \mathrm{~km} \text { de variantes, assim } \\
\text { como o alargamento de } 320 \mathrm{~km} \text { para } \\
\text { bitola de } 1,60 \mathrm{~m} \text {. }\end{array}$ \\
\hline & & $\begin{array}{l}\text { 8- Rodovias } \\
\text { (Pavimentação) }\end{array}$ & $\begin{array}{l}\text { Pavimentação asfáltica de } 5.000 \mathrm{~km} \text { de } \\
\text { rodovia, aumentando assim para } 5.920 \\
\mathrm{~km} \text {, em } 1960 \text {, a rede asfaltada federal, que } \\
\text { era de } 900 \mathrm{~km} \text { em } 1956 \text {. }\end{array}$ \\
\hline & & $\begin{array}{l}\text { 9- Rodovias } \\
\text { (Construção) }\end{array}$ & $\begin{array}{l}\text { Construção de } 12000 \mathrm{~km} \text { de novas } \\
\text { rodovias de primeira classe, aumentando } \\
\text { para } 22.000 \mathrm{~km} \text {, em } 1960 \text {, a rede federal, } \\
\text { que era de } 10.000 \mathrm{~km} \text { em } 1956 \text {. }\end{array}$ \\
\hline & & $\begin{array}{l}\text { 10- Portos e } \\
\text { Drenagem }\end{array}$ & $\begin{array}{l}\text { Reaparelhamento e ampliação de portos e } \\
\text { aquisição de uma frota de dragagem, com } \\
\text { o investimento de } 30.000 .000 \text { de dólares. }\end{array}$ \\
\hline & & $\begin{array}{l}\text { 11- Marinha } \\
\text { Mercante }\end{array}$ & $\begin{array}{l}\text { Ampliação da frota de cabotagem e longo } \\
\text { curso, que era de } 800.000 \mathrm{t} \text { em } 1956 \text {, para } \\
1.100 .000 \mathrm{t} \text {, e aumento da frota de } \\
\text { petroleiros, de } 205.000 \mathrm{t} \text {, para } 585.000 \mathrm{t} \\
\text { em } 1960 \text {. }\end{array}$ \\
\hline & & $\begin{array}{l}12 \text { - Transporte } \\
\text { Aeroviário }\end{array}$ & $\begin{array}{l}\text { Renovação da frota aérea comercial com } \\
\text { financiamento de } 125.000 .000 \text { de dólares. }\end{array}$ \\
\hline \multirow{6}{*}{ ALIMENTAÇÃO } & \multirow{6}{*}{$3,20 \%$} & $\begin{array}{l}13 \text { - Produção } \\
\text { Agrícola (Trigo) }\end{array}$ & $\begin{array}{l}\text { Aumento da produção de trigo de } \\
600.000 \text { para } 1.200 .000 \mathrm{t} \text {. }\end{array}$ \\
\hline & & $\begin{array}{l}14 \text { - Armazéns e } \\
\text { Silos }\end{array}$ & $\begin{array}{l}\text { Construção de armazéns e silos para uma } \\
\text { capacidade estática de } 742.000 \text { t. }\end{array}$ \\
\hline & & $\begin{array}{l}15 \text { - Armazéns } \\
\text { Frigoríficos }\end{array}$ & $\begin{array}{l}\text { Construção e aparelhamento de armazéns } \\
\text { frigoríficos novos para uma capacidade } \\
\text { estática de } 45.000 \mathrm{t} \text {. }\end{array}$ \\
\hline & & $\begin{array}{l}16 \text { - Matadouros } \\
\text { Industriais }\end{array}$ & $\begin{array}{l}\text { Construção de matadouros industriais } \\
\text { com capacidade de abate diário de } 3.550 \\
\text { bovinos e } 1.300 \text { suínos. }\end{array}$ \\
\hline & & $\begin{array}{l}17 \text { - Mecanização da } \\
\text { Agricultura }\end{array}$ & $\begin{array}{l}\text { Aumento do número de tratores em uso } \\
\text { na agricultura de } 45.000 \text { para } 72.000 \\
\text { unidades. }\end{array}$ \\
\hline & & 18 - Fertilizantes & $\begin{array}{l}\text { Aumento da produção de adubos } \\
\text { químicos de } 18.000 \mathrm{t} \text { para } 300.000 \mathrm{t} \text { de } \\
\text { conteúdo de nitrogênio e anidrido } \\
\text { fosfórico. }\end{array}$ \\
\hline $\begin{array}{l}\text { INDÚSTRIAS DE } \\
\text { BASE }\end{array}$ & $20,40 \%$ & 19 - Siderurgia & $\begin{array}{l}\text { Aumento da capacidade de produção de } \\
\text { aço em lingotes de } 1.000 .000 \text { para }\end{array}$ \\
\hline
\end{tabular}

Página 42 Caderno de Ciências Sociais Aplicadas, Vitória da Conquista/BA, vol. 16, n 27, ano 16, p. 39-57, jan/jun 2019. 


\section{Cadernos de Ciências SOCIAIS APLICADAS}

\begin{tabular}{|c|c|c|c|}
\hline & & & $\begin{array}{l}2.000 .000 \mathrm{t} \text { por ano em } 1960 \text {, e para } \\
3.500 .000 \mathrm{t} \text { em } 1965 \text {. }\end{array}$ \\
\hline & & 20 - Alumínio & $\begin{array}{l}\text { Aumento da capacidade de produção de } \\
\text { alumínio de } 2.600 \text { para } 18.800 \text { t em } 1960 \\
\text { e } 52.000 \text { t em } 1962 \text {. }\end{array}$ \\
\hline & & $\begin{array}{l}21 \text { - Metais não } \\
\text { ferrosos }\end{array}$ & $\begin{array}{l}\text { Expansão da produção e refino de metais } \\
\text { não ferrosos (cobre chumbo, estanho, } \\
\text { níquel, etc.). }\end{array}$ \\
\hline & & 22 -Cimento & $\begin{array}{l}\text { Aumento da capacidade de produção de } \\
\text { cimento de } 2.700 .000 \text { para } 5.000 .000 \mathrm{t} \\
\text { anuais em } 1960 .\end{array}$ \\
\hline & & 23 - Álcalis & $\begin{array}{l}\text { Aumento da capacidade de produção de } \\
\text { álcalis de } 20.000 \text { para } 152.000 \mathrm{t} \text { em } 1960 .\end{array}$ \\
\hline & & 24 - Celulose e Papel & $\begin{array}{l}\text { Aumento da produção de celulose de } \\
90.000 \text { para } 260.000 \text { t, de papéis de } \\
\text { imprensa de } 40.000 \text { para } 130.000 \mathrm{t} \text {. }\end{array}$ \\
\hline & & 25 - Borracha & $\begin{array}{l}\text { Aumento da produção de borracha de } \\
23.000 \text { para } 50.000 \mathrm{t} \text {, com o início da } \\
\text { fabricação da borracha sintética. }\end{array}$ \\
\hline & & 26 - Minério & $\begin{array}{l}\text { Aumento da exportação de minério de } \\
\text { ferro de } 2.500 .000 \text { para } 8.000 .000 \mathrm{t} \text { e } \\
\text { preparação para exportação de } 20.000 . \\
000 \text { de toneladas no próximo quinquênio. }\end{array}$ \\
\hline & & $\begin{array}{l}27- \\
\text { Automobilística }^{6}\end{array}$ & $\begin{array}{l}\text { Implantação da indústria automobilística } \\
\text { para produzir } 170.000 \text { veículos } \\
\text { nacionalizados em } 1960 .\end{array}$ \\
\hline & & $\begin{array}{l}28 \text { - Construção } \\
\text { Naval }\end{array}$ & $\begin{array}{l}\text { Implantação da indústria de construção } \\
\text { naval. }\end{array}$ \\
\hline & & $\begin{array}{l}29 \text { - Mecânica e de } \\
\text { Material Elétrico } \\
\text { Pesado }\end{array}$ & $\begin{array}{l}\text { Implantação e expansão da indústria de } \\
\text { material elétrico e de mecânica pesada. }\end{array}$ \\
\hline EDUCAÇÃO & 3,4 & 30 - Pessoal Técnico & $\begin{array}{l}\text { Intensificação da formação de pessoal } \\
\text { técnico e orientação da Educação para o } \\
\text { Desenvolvimento, com a instalação de } \\
\text { institutos de formação especializada. }\end{array}$ \\
\hline
\end{tabular}

Fonte: Elaboração própria com base nas informações do documento oficial elaborado pelo Conselho de Desenvolvimento brasileiro para divulgar a situação do Plano de Metas (1958).

Embora não tenha sido incluída nesse conjunto de metas acima elencadas, a construção de Brasília representou um compromisso de campanha de Juscelino Kubitschek, e por isso é conhecida como uma meta-síntese, símbolo do plano. A sua concretização custaria à economia brasileira 2,3\% do seu Produto Interno Bruto (PIB). Tal empreendimento, porém, encontrava suporte no conceito de

\footnotetext{
${ }^{6}$ A meta 27 (indústria automobilística) é lembrada como uma das mais representativas dos anos JK devido à importância que a sua realização significava para as demais metas, bem como aos resultados obtidos na sua execução, como será evidenciado na próxima seção. Nas palavras de Juscelino Kubitschek de Oliveira (1955, p.156): “O desenvolvimento das redes rodoviárias e a expansão dos núcleos urbanos ampliariam o campo de atividade dos veículos automóveis, tornando-os instrumentos utilíssimos às relações humanas e ao intercambio de riquezas".
}

Página 43 Caderno de Ciências Sociais Aplicadas, Vitória da Conquista/BA, vol. 16, n 27, ano 16, p. 39-57, jan/jun 2019. 
ponto de germinação ${ }^{7}$, uma vez que propiciaria maior desenvolvimento da região Centro-Oeste do Brasil.

Os investimentos diretos do governo direcionados à efetivação das metas já citadas foram distribuídos pelos setores da seguinte forma: Energia (43,4\%), transporte (29,6\%), indústrias de base $(20,4 \%)$, alimentação $(3,2 \%)$, e educação $(3,4 \%) .{ }^{8}$ Para os idealizadores do Plano de Metas, a ideia de concentrar 73\% desses investimentos no binômio energia e transportes era explicada pelo fato de esses setores representarem necessidades permanentes da população, devendo assim ser considerados prioritários para desenvolvimento econômico brasileiro. No entanto, para muitos críticos do plano, essa era uma estratégia utilizada para atrair capitais estrangeiros para os setores mais estratégicos da economia brasileira, dada a capacidade retroalimentadora (pontos de germinação) de ambos para gerar demandas e, consequentemente, atrair investimentos privados para outros setores, como os de bens de capital, bens de consumo durável etc. ${ }^{9}$

Tendo em vista o grave quadro de tensões políticas e desequilíbrios crescentes vivenciados pela economia brasileira no biênio 1954-55, vê-se que a implementação do Plano de Metas dependia primeiramente da criação de instrumentos de política econômica, organismos e outros mecanismos de ação capazes de resolver antigos problemas internos, tais como: financiamento, acesso às tecnologias, centralização e controle das decisões etc. Estes contribuiriam posteriormente para a formação daquilo que ficou conhecida como a administração paralela do governo JK.

Mostra-se, a seguir, de que forma o Estado brasileiro "superou" tais dificuldades e deu continuidade a sua estratégia de desenvolvimento.

\section{Financiamento}

Ao analisar o conjunto de reformas financeiras implementadas na economia brasileira nos governos que antecederam $\mathrm{JK}$, percebe-se que ambas foram incapazes de reestruturar o sistema financeiro nacional de forma a criar um padrão de financiamento autônomo. Diante disso, para colocar o Plano de Metas em prática, o Estado brasileiro, além dos recursos próprios, optou por adotar um

\footnotetext{
${ }^{7}$ A definição desse conceito pode ser encontrada em LESSA, C. Quinze anos de política econômica. 4.ed. São Paulo: Brasiliense, 1983. Para o autor, pontos de germinação faz referência a pontos onde o investimento tem a capacidade de gerar demandas e produzir investimentos, sustentando assim a taxa de crescimento do país.

8 Tais informações estão disponibilizadas in: Brasil. Presidência da República. Conselho do Desenvolvimento. Programa de Metas. Rio de Janeiro, 1958.

${ }_{9}$ Nesse grupo de autores que criticaram o Plano de Metas, bem como seus instrumentos de execução, estão alguns citados neste trabalho, como: CAMPOS, op. cit., 2009; LIMA, op. cit., 1958; RUCHERT, op. cit., 1981.
}

Página 44 Caderno de Ciências Sociais Aplicadas, Vitória da Conquista/BA, vol. 16, n 27, ano 16, p. 39-57, jan/jun 2019. 
padrão de financiamento que trilhava pelas linhas de menor resistência, ou seja, que aderia ao financiamento externo mediante os influxos de Investimento Direto Estrangeiro (IDE) e empréstimos externos (CAMPOS, 2009). Por um lado, essa escolha do Estado despertava a confiança dos possíveis investidores e financiadores estrangeiros, os quais desejavam ampliar e diversificar seus investimentos no Brasil (BENEVIDES, 1976). Por outro, mantinha a economia brasileira dependente da entrada contínua de capitais estrangeiros, não levando em consideração as implicações internas de tal escolha.

Contudo, o volume de financiamento externo adquirido por meio do financiamento externo não foi suficiente, de modo que se fez necessário criar fontes internas de financiamento, tais como: o sistema tributário, as emissões primárias - "financiamento inflacionário" - e os fundos setoriais provenientes do Banco Nacional de Desenvolvimento (BNDE), os quais se dividiam em fundos especiais e fundos vinculados. Os primeiros eram compostos por seu capital e reservas, pelo Fundo do Reaparelhamento Econômico, por depósitos compulsórios de vários tipos e pelo Fundo Especial de Juros, Amortizações e Resgate das Obrigações do Reaparelhamento Econômico. Os recursos vinculados procediam da arrecadação de taxas e impostos federais destinados a programas setoriais específicos, cuja administração estava sob o comando do BNDE em parceria com empresas privadas $\left(\right.$ DIAS, 1996) ${ }^{10}$. Para essas empresas, tais fundos garantiriam a sua lucratividade nas diferentes etapas do processo de execução dos empreendimentos do Plano de Metas, sobretudo daqueles existentes nos setores mais estratégicos da economia brasileira ${ }^{11}$.

Em suma, mesmo que essa opção escolhida pelo Estado brasileiro pudesse trazer resultados positivos para a industrialização brasileira em um primeiro momento, o descuido para com os sucessivos déficits no balanço de pagamentos brasileiro tenderia a gerar uma série de consequências desestabilizadoras, de maneira a impedir a continuidade da execução do plano, como ficou comprovado no início da década de 1960.

\footnotetext{
$10 \mathrm{O}$ referido autor enalteceu a importância do BNDE no desenvolvimento da indústria brasileira na segunda metade dos anos 50: "Nesse sentido, é impossível subestimar a participação do BNDE na formulação do plano e no financiamento de projetos, que foi de inestimável importância para o cumprimento de diversas metas de produção e a instalação de capacidade industrial" (p.05).

${ }^{11}$ Isso porque eles "supriam os recursos de longo prazo (juntamente com o Branco do Brasil, as únicas instituições a fazêlo), a juros baixos sujeitos à carência, o que na conjuntura inflacionária, significava uma taxa real de juros negativa" (SOCHACZEWSKI, 1993, p. 103).
}

Página 45 Caderno de Ciências Sociais Aplicadas, Vitória da Conquista/BA, vol. 16, n 27, ano 16, p. 39-57, jan/jun 2019. 


\section{Acesso às tecnologias}

Ainda no tocante às dificuldades encontradas na fase de implementação do Plano de Metas, estava o problema relacionado à incapacidade da economia brasileira desenvolver uma autonomia tecnológica suficiente para instalar no país indústrias produtoras de bens de produção que atuassem na construção da infraestrutura adequada para a execução das metas setoriais propostas (TIRONI, 1979) ${ }^{12}$. Isso nos revela a centralidade assumida pelo desenvolvimento tecnológico no processo de modernização da estrutura produtiva brasileira naquela fase em que se pretendia impulsionar a industrialização pesada a qualquer custo.

A solução para esse problema do atraso tecnológico, refletido principalmente na ausência de autonomia do capital nacional, foi encontrada na importação de equipamentos, tecnologias e bens de capital, a qual foi autorizada pela Instrução 113 da Superintendência da Moeda e do Crédito (SUMOC), promulgada no governo de Café Filho em 1955 (DREIFUSS, 1986). Esse marco regulatório permitia a entrada de capitais estrangeiros destinados à ampliação da capacidade produtiva da indústria brasileira sem cobertura cambial, ou seja, sem o pagamento de divisas, concomitantemente, acabava com os critérios de seletividade para os investimentos estrangeiros que tinham interesse no país (CAMPOS, 2009).

Em outros termos, por meio dessa Instrução as empresas multinacionais teriam livre mobilidade para sair de seus países de origem, ingressar no espaço econômico brasileiro e instalar aqui subsidiárias para atuar na criação de plantas produtivas, utilizando tecnologias importadas, sem nenhuma despesa cambial. Isso contribuiria para a realização das metas setoriais propostas pelo plano em questão, de modo a viabilizar a internacionalização de capitais na economia brasileira.

De fato, a política do capital estrangeiro se colocou como única via aberta à superação dessas duas dificuldades. O conjunto de práticas sugeridas para a obtenção de recursos externos e de novas tecnologias criaria as condições para o êxito do Plano de Metas, ainda que viessem a incorrer em alto custo para a nação.

\footnotetext{
12 “Tratava-se, portanto, de um problema básico na formação do Departamento de Bens de Produção constituído pela permanência de um atraso tecnológico relativo que impedia uma articulação mais estreita do setor de bens de capital com os demais subsetores da indústria de bens de produção (siderurgia, metalurgia, petroquímica, energia elétrica, etc.), como também com os outros setores do sistema industrial (TIRONI, 1979, p.11).
}

Página 46 Caderno de Ciências Sociais Aplicadas, Vitória da Conquista/BA, vol. 16, n 27, ano 16, p. 39-57, jan/jun 2019. 


\section{Centralização e controle de decisões}

Após superar essas dificuldades iniciais já apresentadas, Juscelino Kubitschek decidiu criar um aparato burocrático para atuar na coordenação e controle do processo decisório, e também na remoção dos obstáculos encontrados na implementação do Plano de Metas, mantendo os benefícios do Poder Executivo. A intenção do governo foi criar um sistema interno de planejamento que pudesse direcionar a política econômica desde a sua fase de elaboração até a sua execução defendendo os interesses nacionais.

Desse modo, esse "aparato" também conhecido como "administração paralela”, representaria um esquema racional, dentro de um sistema de planejamento, coordenado pelo Conselho de Desenvolvimento (CD), o qual era formado por órgãos estatais existentes, como: a Carteira de Comércio Exterior do Banco do Brasil (CACEX), o Banco Nacional de Desenvolvimento (BNDE) e a Superintendência da Moeda e do Crédito (SUMOC), mais os novos órgãos executivos ou de assessoria, os Grupos Executivos (GE), os Grupos de Trabalho (GT) e o Conselho de Política Aduaneira (CPA) (LESSA, 1983). ${ }^{13}$

Nessa estrutura, cada uma dessas partes integrantes teria funções específicas. O CD, órgão central de planejamento, centralizaria o processo de formulação da política econômica de forma a oferecer as condições institucionais de comando e coordenação executivas ${ }^{14}$. Os grupos de trabalho, compostos por representantes dos órgãos-chave da administração de cada setor, como por exemplo, da CACEX, da SUMOC, da Carteira de Cambio do Banco do Brasil, do BNDE, da Confederação Nacional da Indústria, dos Ministérios etc., cumpririam o papel de assessorar a preparação de projetos de lei ou de regulamentação sobre um determinado projeto em vista, solucionando assim os problemas relacionados a financiamento e verbas orçamentárias (LAFER, 2002).

Os grupos executivos, formados por administradores estatais e, sobretudo, por industriais do setor privado brasileiro e internacional, seriam os organismos responsáveis pela concessão e manipulação dos recursos necessários à realização das metas em diferentes setores industriais, tais como a oferta de tecnologia e/ou oferta de recursos financeiros, sendo que a maior parte destes era de origem

\footnotetext{
13 LESSA, op. cit., 1983. Sobre a importância da administração paralela no Plano de Metas, Ver LEOPOLDI, M. A. Crescendo em meio à incerteza: a política econômica do Governo JK. In: (Org.) GOMES, A. C. O Brasil de JK. Rio de Janeiro: Fundação Getúlio Vargas/ CPDOC, 1991.

${ }^{14}$ Criado em $1^{\circ}$ de Fevereiro de 1956 pelo Decreto no 38.744 , o Conselho de Desenvolvimento seria o órgão coordenador da formulação e da execução do Plano de Metas, composto pelos ministros, chefes das casas Civil e Militar, o presidente do Banco do Brasil e o presidente do BNDE. Sobre o funcionamento deste órgão, ver LOPES, L. Memórias do Desenvolvimento. Centro de Memória da Eletricidade no Brasil, Rio de Janeiro, 1991.
}

Página 47 Caderno de Ciências Sociais Aplicadas, Vitória da Conquista/BA, vol. 16, n 27, ano 16, p. 39-57, jan/jun 2019. 
externa. Desses grupos executivos existentes, Leopoldi (1991) destacou os mais atuantes deles: o Grupo Executivo da Indústria Automobilística (GEIA), o Grupo Executivo da Indústria da Construção Naval (GEICON), Grupo Executivo da Indústria Mecânica Pesada (GEIMAPE), Grupo Executivo de Máquinas Agrícolas e Rodoviárias (GEIMAR), Grupo Executivo da Indústria de Material Ferroviário (GEIMF) e da Assistência à Média e Pequena Indústria (GEAMP).

Donde a importância dos GE centralizando a ação administrativa - em termos de licenças de importação, cambio, financiamentos, avais, e garantias etc. -, ao mesmo tempo em que descentralizava a execução de suas decisões. Estes grupos possuíam uma autonomia orçamentária, o que lhes poderia garantir uma grande margem de flexibilidade operacional, caso os interesses clientelísticos não fossem levados em consideração (BENEVIDES, 1976, p. 230).

E, por fim, Benevides (1976) enalteceu a importância do CPA, constituído por representantes dos empresários brasileiros e estrangeiros, dos trabalhadores e do governo. O referido conselho possuiria uma autonomia suficiente para formular, em parte, a política de importação do país, alterando as alíquotas de importação e as tarifas aduaneiras, o que viria a beneficiar as empresas estatais, as privadas nacionais e estrangeiras.

Dentro dessa divisão de tarefas, articulada pelo Estado, formar-se-ia um tripé desenvolvimentista, composto pelo Estado, capital estrangeiro e capital privado nacional. Teoricamente, a função de cada um destes seria orientar os campos de atuação das indústrias dos diferentes ramos durante o ciclo expansivo (SERRA, 1998). Assim, caberia ao capital privado nacional, considerado a "pata" mais frágil do tripé, uma proteção especial que consistia no recebimento de incentivos para sua expansão na indústria de bens de capital e nos setores fornecedores de bens e serviços para a expansão das filiais das empresas multinacionais, tais como: transporte, energia, e insumos básicos.

A eficácia dessa proposta de centralizar os processos de formulação e execução do Plano de Metas por meio da administração paralela e dos demais instrumentos criados pelo Estado nessa fase poderia resultar em um elevado ritmo de crescimento econômico da economia brasileira. Para tanto, far-se-ia necessário que o Estado brasileiro submetesse os capitais estrangeiros que entraram no espaço econômico brasileiro nesse ínterim aos desígnios nacionais, de maneira a sobrepor os seus interesses aos interesses privados.

Entretanto, isso não ocorreu, de fato, visto que no decorrer desse processo esses capitais ingressados na forma de empréstimos, investimentos diretos, filiais de empresas multinacionais,

Página 48 Caderno de Ciências Sociais Aplicadas, Vitória da Conquista/BA, vol. 16, n 27, ano 16, p. 39-57, jan/jun 2019. 
importações etc., adquiriram internamente autonomia para controlar o desenvolvimento dos setores mais estratégicos da economia, como será mostrado a seguir.

\section{Execução e resultados}

Embora as metas mencionadas na primeira parte deste trabalho representassem um considerável esforço do Estado brasileiro na integração do sistema industrial brasileiro, na prática, elas se colocavam como uma tentativa formal de consolidação das intenções de Juscelino Kubitschek para alcançar o desenvolvimento econômico, mediante a relação estabelecida pelas empresas estatais com o setor privado brasileiro e estrangeiro (MELLO; SOUZA, 1968). Nesse processo, as empresas estatais criavam as condições infraestruturais mínimas para o desenvolvimento do setor privado, uma vez que garantiam a este o fornecimento de serviços e insumos básicos necessários a sua expansão.

Nessa época, o setor produtivo estatal emerge significativamente através das diretrizes traçadas pelo Plano de Metas, possibilitando vários projetos na área de infraestrutura (energia, transporte) e insumos básicos. Essa infraestrutura seria condição prévia para que o setor privado se desenvolvesse, tornando-se também um dos fatores necessários para a instalação de empresas multinacionais no País. E essas empresas direcionam seus investimentos para a indústria de bens duráveis, implementando diversos projetos na área. Como o setor de bens de capital não estava totalmente consolidado, os investimentos estrangeiros vieram de forma direta. As empresas multinacionais tiveram, ainda, uma série de vantagens para se instalarem no País, em termo de estímulos fiscais e facilidades para saída de lucros (RÜCKERT, 1981, p. 79-80).

Por intermédio da ação das empresas estatais, os capitais estrangeiros, já favorecidos pela Instrução no 113 da SUMOC e por outras vantagens proporcionadas pelo Estado, obtiveram liberdade e autonomia para "estabelecer novos laços de poder econômico dentro do aparelho de Estado, além de novas formas de comunicação com os centros de decisão podendo inclusive controlar setores estratégicos da economia nacional” (DREIFUSS, 1986, p. 137). Isso mostra como esse crescimento da participação desses capitais nesse período foi fundamental para que o Plano de Metas atingisse os resultados propostos.

A Tabela 1 apresenta a quantidade desses recursos estrangeiros direcionados à economia brasileira, na forma de financiamentos e investimentos diretos, no período concernente à execução do Plano de Metas (1956 - 1961), evidenciando os setores nos quais estes se fizeram mais presentes.

Página 49 Caderno de Ciências Sociais Aplicadas, Vitória da Conquista/BA, vol. 16, n 27, ano 16, p. 39-57, jan/jun 2019. 


\section{- Cadernos de CiêncIas SOCIAIS APLICADAS}

Tabela 1: recursos estrangeiros direcionados ao Plano de Metas 1956/61 (Bilhões de Cr\$)

\begin{tabular}{lcccc}
\hline Itens/Setores & $\begin{array}{c}\text { Financiamento } \\
\text { pela SUMOC }\end{array}$ & $\begin{array}{c}\text { Investimentos } \\
\text { Diretos }\end{array}$ & Total do Setor & $\begin{array}{c}\text { Percentual de } \\
\text { cada setor no } \\
\text { total }\end{array}$ \\
\hline Energia & 403,8 & 0,7 & 404,5 & 17,65 \\
Transporte & 535,8 & 1,9 & 537,7 & 23,45 \\
Alimentação & 112,3 & 20,6 & 132,9 & 5,8 \\
Indústrias de & 939,6 & 279,0 & $1.218,6$ & 53,10 \\
Base & $1.991,5$ & 302,2 & & 100 \\
Total & & & $2.293,7$ & \\
\hline
\end{tabular}

Fonte: Lessa (1983).

A explicação para essa grande quantia de capitais estrangeiros aplicada no setor de indústrias de base, tanto na forma de financiamento, quanto na forma de investimentos diretos, está na centralidade que essa indústria possuía no atendimento das demandas do setor privado. Em outras palavras, ela era responsável por produzir as matérias-primas (ferro, aço, borracha, níquel, cimento, cobre, estanho, alumínio, etc.,) utilizadas no desenvolvimento de outras áreas que estavam sob o controle do setor privado brasileiro e internacional.

Como consequência de tamanha atenção recebida, tanto pelo Estado, quanto pelos capitais estrangeiros, as metas relacionadas ao setor de indústrias de bases foram as que mais atingiram os resultados propostos no Plano de Metas, em detrimento das demais, como pode ser observado no Quadro 2.

Quadro 2: Resultados Alcançados pelo Plano de Metas

\begin{tabular}{|c|c|c|c|}
\hline SETOR & $\begin{array}{l}\text { INVESTIMENTO } \\
\text { ESTATAL } \\
\text { PLANEJADO (\%) }\end{array}$ & META & RESULTADOS ATINGIDOS \\
\hline \multirow{5}{*}{ ENERGIA } & \multirow{5}{*}{$43,40 \%$} & 1 - Energia Elétrica & $\begin{array}{l}\text { A capacidade alcançou } 4.770 \text { mil KW; } \\
95,4 \% \text { da meta. }\end{array}$ \\
\hline & & 2 - Energia Nuclear & $\begin{array}{l}\text { Foi construído e inaugurado o reator de } \\
\text { Pesquisas do IEA (Instituto de Energia } \\
\text { Atômica na USP (Universidade de São } \\
\text { Paul). }\end{array}$ \\
\hline & & 3 - Carvão Mineral & $\begin{array}{l}\text { A capacidade alcançou } 2.199 \text { mil t/ano; } \\
26,7 \% \text { da meta. }\end{array}$ \\
\hline & & $\begin{array}{l}\text { 4- Petróleo } \\
\text { (Produção) }\end{array}$ & $\begin{array}{l}\text { A capacidade alcançou } 75.500 \text { barris/dia; } \\
75,5 \% \text { da meta. }\end{array}$ \\
\hline & & 5 - Petróleo & A capacidade alcançou 218 mil barris/dia; \\
\hline
\end{tabular}

Página 50 Caderno de Ciências Sociais Aplicadas, Vitória da Conquista/BA, vol. 16, n 27, ano 16, p. 39-57, jan/jun 2019. 


\section{- Cadernos de Ciênclas SOCIAIS APLICADAS}

\begin{tabular}{|c|c|c|c|}
\hline & & (Refinação) & $66,7 \%$ da meta. \\
\hline \multirow{7}{*}{ TRANSPORTES } & \multirow{7}{*}{$29,60 \%$} & $\begin{array}{c}\text { 6-Ferrovias } \\
\text { (Reaparelhamento) }\end{array}$ & $\begin{array}{l}\text { A capacidade no seu conjunto estimada } \\
\text { foi de } 76 \% \text { da meta prevista. }\end{array}$ \\
\hline & & $\begin{array}{l}7 \text { - Ferrovias } \\
\text { (Construção) }\end{array}$ & $\begin{array}{l}\text { A capacidade alcançada foi de } 826,5 \mathrm{Km} \text {; } \\
39,4 \% \text { da meta. }\end{array}$ \\
\hline & & $\begin{array}{c}8 \text { - Rodovias } \\
\text { (Pavimentação) }\end{array}$ & $\begin{array}{l}\text { A capacidade alcançada foi de } 6.202 \mathrm{~km} \text {, } \\
24 \% \text { acima da meta. }\end{array}$ \\
\hline & & $\begin{array}{l}9 \text { - Rodovias } \\
\text { (Construção) }\end{array}$ & $\begin{array}{l}\text { A capacidade alcançada foi de } 14.970 \mathrm{~km} \text {, } \\
24,8 \% \text { acima da meta. }\end{array}$ \\
\hline & & $\begin{array}{l}10 \text { - Portos e } \\
\text { Drenagem }\end{array}$ & $\begin{array}{l}\text { A capacidade alcançada correspondeu a } \\
56,1 \% \text { da meta }\end{array}$ \\
\hline & & $\begin{array}{l}11 \text { - Marinha } \\
\text { Mercante }\end{array}$ & $\begin{array}{l}\text { A capacidade atingida no seu conjunto } \\
\text { correspondeu a } 90,9 \% \text { da meta. }\end{array}$ \\
\hline & & $\begin{array}{c}12 \text { - Transporte } \\
\text { Aeroviário }\end{array}$ & $\begin{array}{l}\text { A capacidade alcançada foi de } 13 \\
\text { unidades à frota aérea; } 31 \% \text { da meta. }\end{array}$ \\
\hline \multirow{6}{*}{ ALIMENTAÇÃO } & \multirow{6}{*}{$3,20 \%$} & $\begin{array}{l}13 \text { - Produção } \\
\text { Agrícola (Trigo) }\end{array}$ & $\begin{array}{l}\text { A capacidade alcançada foi de } 370 \text { mil } \\
\text { toneladas, ou seja, queda na capacidade } \\
\text { produtiva em relação a } 1955 \text { que era de } \\
871.000 \mathrm{t} \text {. }\end{array}$ \\
\hline & & 14 - Armazéns e Silos & $\begin{array}{l}\text { A capacidade alcançada foi de } 569.233 \\
\text { toneladas; } 76,7 \% \text { da meta. }\end{array}$ \\
\hline & & $\begin{array}{l}15 \text { - Armazéns } \\
\text { Frigoríficos }\end{array}$ & $\begin{array}{l}\text { A capacidade alcançada foi de } 8.014 \\
\text { toneladas; } 17,8 \% \text { da meta. . }\end{array}$ \\
\hline & & $\begin{array}{l}16 \text { - Matadouros } \\
\text { Industriais }\end{array}$ & $\begin{array}{l}\text { A capacidade alcançada foi de } 2.100 \\
\text { bovinos e } 700 \text { suínos; } 59,2 \% \text { e } 53,8 \% \text { da } \\
\text { meta respectivamente.. }\end{array}$ \\
\hline & & $\begin{array}{l}17 \text { - Mecanização da } \\
\text { Agricultura }\end{array}$ & $\begin{array}{l}\text { A capacidade alcançada foi de } 77.362 \text {, em } \\
7,2 \% \text { acima da meta. }\end{array}$ \\
\hline & & 18 - Fertilizantes & $\begin{array}{l}\text { A capacidade alcançada foi de } 290 \text { mil } \\
\text { toneladas, } 141,7 \% \text { acima da meta. }\end{array}$ \\
\hline \multirow{6}{*}{$\begin{array}{c}\text { INDÚSTRIAS } \\
\text { DE BASE }\end{array}$} & \multirow{6}{*}{$20,40 \%$} & 19 - Siderurgia & $\begin{array}{l}\text { A capacidade alcançada foi de } 2.279 \mathrm{mil} \\
\text { toneladas de lingotes, } 14 \% \text { acima da meta. }\end{array}$ \\
\hline & & 20 - Alumínio & $\begin{array}{l}\text { A capacidade alcançada foi de } 16.573 \\
\text { toneladas, } 92,1 \% \text { da meta. }\end{array}$ \\
\hline & & $\begin{array}{l}21 \text { - Metais não } \\
\text { ferrosos }\end{array}$ & $\begin{array}{l}\text { A capacidade alcançada de cobre, } \\
\text { chumbo, estanho e níquel foram } \\
\text { aumentadas em, respectivamente } 203,8 \% \text {; } \\
147,7 \% ; 143,6 \% \text { acima da meta. }\end{array}$ \\
\hline & & 22 - Cimento & $\begin{array}{l}\text { A capacidade alcançada foi de } 4.369 .250 \\
\text { toneladas, } 87,4 \% \text { da meta. }\end{array}$ \\
\hline & & 23 - Álcalis & $\begin{array}{l}\text { A capacidade alcançada foi de } 152 \text { mil } \\
\text { toneladas, } 100 \% \text { da meta. }\end{array}$ \\
\hline & & 24 - Celulose e Papel & $\begin{array}{l}\text { A capacidade alcançada foi de } 200.237 \mathrm{t} \\
\text { de celulose e } 65.760 \text { de papel, sendo }\end{array}$ \\
\hline
\end{tabular}

Página 51 Caderno de Ciências Sociais Aplicadas, Vitória da Conquista/BA, vol. 16, nº 27, ano 16, p. 39-57, jan/jun 2019. 


\section{Cadernos de Ciências SOCIAIS APLICADAS}

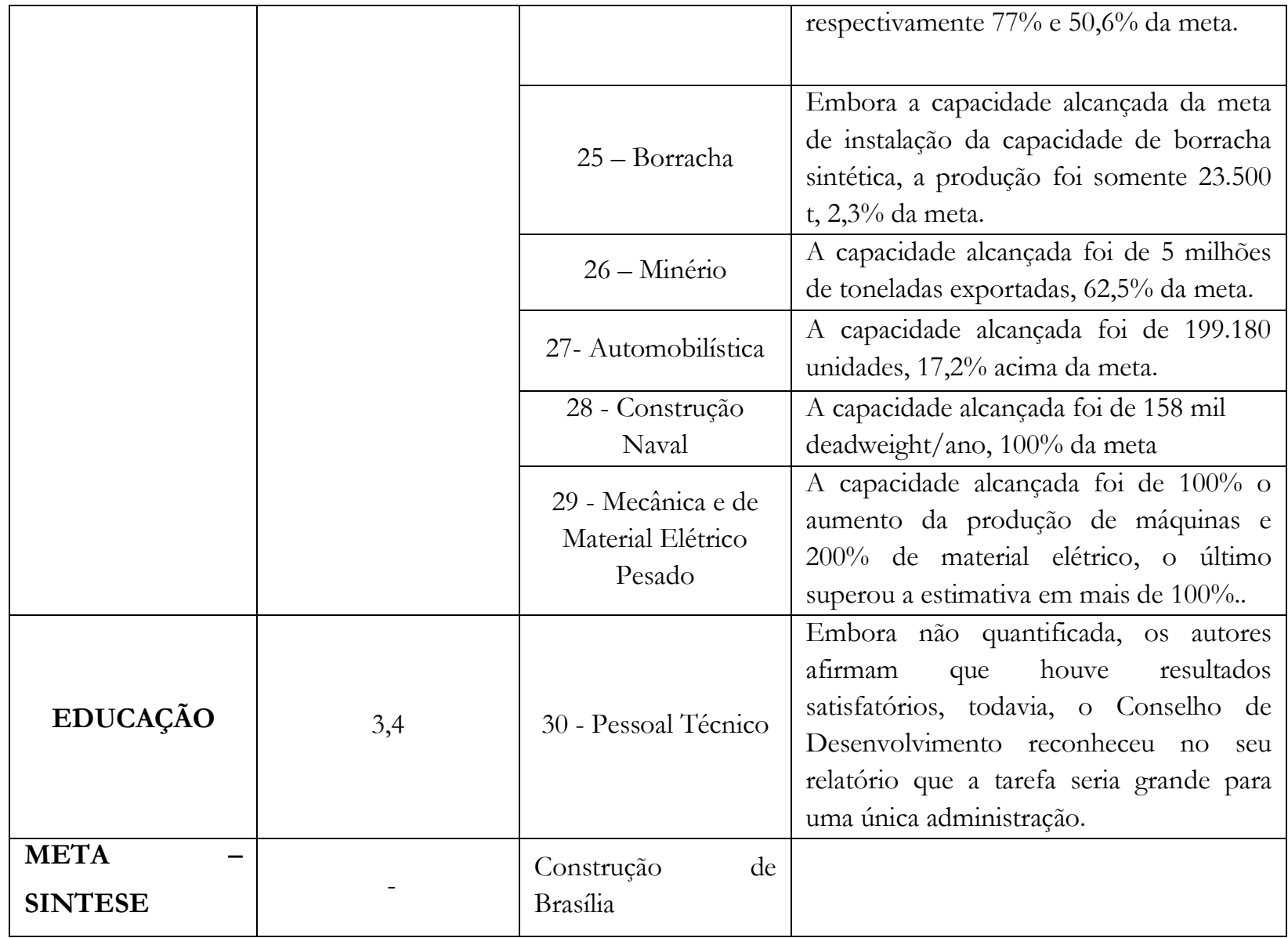

Fonte: Elaboração própria a partir de informações disponibilizadas em: BENEVIDES, op. cit., 1976; FARO, C.; QUADROS, S. op. cit., 1991; LAFER, op. cit., 2002; LEOPOLDI, M. A. op. cit., 1991; LESSA, op. cit, 1983.

Com base nos resultados apresentadas no Quadro 2, nota-se um ciclo expansivo do setor industrial brasileiro, representado no aumento da capacidade produtiva das indústrias siderúrgica (141\%), alumínio (92,1\%), cimento (87,4\%), álcalis (100\%), celulose (77\%), mecânica (200\%), material elétrico (100\%), metais não ferrosos (acima de 100\%), automobilística $(117,2 \%)$ e de construção naval $(100 \%)$, as quais praticamente atingiram ou superaram todas as estimativas previstas para o período 1956-1961. Faro e Quadros (1991) afirmaram que esse sucesso setorial alcançado pelo Plano de Metas pode ser ilustrado pela taxa média de crescimento do PIB brasileiro de 8,27\% no período 1956-1961, contra 6,06\% no quinquênio anterior, e 3,49\% no período 1962-1966.

De fato, o aumento da produção industrial, assim como dos investimentos nesse setor de insumos básicos impulsionaram a realização de algumas metas dos setores de energia, transporte e alimentação, pois forneciam os materiais para serem utilizados nos respectivos projetos desses setores, fazendo avançar a modernização da economia brasileira. No setor energético, por exemplo, grande

Página 52 Caderno de Ciências Sociais Aplicadas, Vitória da Conquista/BA, vol. 16, n 27, ano 16, p. 39-57, jan/jun 2019. 
parte das metas atingiu elevados percentuais de realização diante do planejado, tais como: os setores de energia elétrica $(95,4 \%)$, produção de petróleo $(75,5 \%)$, com exceção do carvão mineral que atingiu apenas $26,7 \%$ da meta inicial proposta.

No setor de transportes os resultados mais significativos ocorreram nos setores de construção e pavimentação de rodovias e na marinha mercante, os quais cresceram 124,8\%, 124 \% e 90, 9\%, respectivamente. Por outro lado, as metas referentes à construção de ferrovias e ao transporte aeroviário não alcançaram resultados satisfatórios, devido à falta de investimentos externos, atingindo apenas $39,4 \%$ e $31 \%$ das metas propostas. Ademais, no setor de alimentação as metas que mais se destacaram foram: 14 (armazéns e silos), 17 (mecanização da agricultura) e 18 (fertilizantes), responsáveis por atingirem $76,7 \%, 117,2 \%$ e $141,7 \%$, respectivamente, enquanto as outras tiveram resultados pouco significativos .

Por trás desse "progresso", que ocorreu na indústria brasileira e nos demais setores de infraestrutura crescia também o acúmulo de sucessivos déficits no balanço de pagamentos, produzidos em grande parte pelas remunerações externas pagas pela economia brasileira aos capitais estrangeiros que ingressaram aqui após a publicação da Instrução no 113 da SUMOC, tais como: remessas de lucros, juros, dividendos, royalties e assistência técnica.

De fato, ao drenar para o exterior todos os lucros produzidos, esse tipo de investimento criou um ônus cada vez mais pesado para a economia do país (LIMA, 1958). Basta observar a Tabela 2 para compreender o problema que se gestou nesse período.

Tabela 2: Balança de Pagamentos da economia brasileira 1956-1961 (US\$ milhões)

\begin{tabular}{ccccccc}
\hline & $\mathbf{1 9 5 6}$ & $\mathbf{1 9 5 7}$ & $\mathbf{1 9 5 8}$ & $\mathbf{1 9 5 9}$ & $\mathbf{1 9 6 0}$ & $\mathbf{1 9 6 1}$ \\
\hline Balança Comercial & 437 & 107 & 65 & 72 & -23 & 113 \\
Serviços & -369 & 358 & -309 & -373 & -459 & -350 \\
Merc. e Serviços & 68 & -251 & -244 & -301 & -482 & -237 \\
Transf. Unilaterais & -11 & -13 & -4 & -10 & 4 & 15 \\
Transações Correntes & 57 & -264 & -248 & -311 & -478 & -222 \\
Capitais & 151 & 255 & 184 & 182 & 58 & 288 \\
Erros e omissões & -14 & -171 & -189 & -25 & 10 & 49 \\
Saldo & 194 & -180 & -253 & -154 & -410 & 115
\end{tabular}

Fonte: Relatórios do Banco Central, apud LEOPOLDI, 2002, pág. 123.

Página 53 Caderno de Ciências Sociais Aplicadas, Vitória da Conquista/BA, vol. 16, n 27, ano 16, p. 39-57, jan/jun 2019. 
Esses dados apresentados revelam que o planejamento econômico proposto por Juscelino Kubitschek, por meio da administração paralela, embora buscasse orientar o desenvolvimento industrial setorialmente, não conseguia impor uma lógica centralizada no processo de execução do Plano de Metas. A atuação do Estado nessa fase, por meio do planejamento, em vez de assumir o controle da industrialização pesada, criava condições para a entrada de capitais estrangeiros, sob a forma de investimentos diretos, importações subsidiadas, empréstimos e principalmente na forma de filiais de empresas multinacionais.

Desse modo, à medida que os projetos setoriais propostos pelo Plano de Metas se concretizavam, novas filiais de grandes empresas multinacionais se instalavam na economia brasileira e vice-versa, de maneira a controlar o processo de execução das metas setoriais. No setor industrial, por exemplo, a atuação dos grupos executivos, em consonância com o Estado brasileiro, possibilitou a participação do investimento direto estrangeiro na construção da indústria automobilística, construção naval, siderúrgica, mecânica e de material elétrico, química etc. (LIMA, 1958). Nos outros setores, a participação desse investimento externo foi bem inferior, quando comparado ao setor industrial, o que revela a funcionalidade do capital estrangeiro nos setores mais estratégicos para o desenvolvimento econômico do país.

Nos anos finais da década de 1950 e início dos anos 1960, devido às próprias particularidades e debilidades da formação do capitalismo brasileiro, a economia brasileira viveu uma fase marcada por um conjunto de problemas de ordem estrutural e conjuntural que se avolumaram ao longo da década, resultando na sua desaceleração cíclica (SERRA, 1998). Isto é, aliado ao desenvolvimento do mercado interno brasileiro ocorrido via industrialização, cresceu o acúmulo de déficits no balanço de pagamentos, causados pela necessidade de reservas cambiais em dólar para remunerar os investimentos diretos estrangeiros,

Em virtude disso, houve um declínio da entrada desses investimentos, de modo que os setores que conduziam o crescimento brasileiro da época "defrontaram-se com o enfraquecimento do mercado interno, apresentando uma sobreoferta de produtos em relação à demanda esperada" (CAMPOS, 2009, p. 78). Esse crescimento da capacidade ociosa da indústria brasileira fez com que o produto interno brasileiro caísse de 10,8, em 1958, para 6,6, em 1962. Daí em diante, uma série de desajustes internos (estrangulamento do câmbio, aceleração da inflação, aumento da dívida externa) sucedeu na economia brasileira, os quais corroboraram o malogro do projeto desenvolvimentista de Juscelino Kubitschek.

Página 54 Caderno de Ciências Sociais Aplicadas, Vitória da Conquista/BA, vol. 16, n 27, ano 16, p. 39-57, jan/jun 2019. 
Uma conjuntura adversa como essa revelou a incapacidade do projeto "juscelinista" de continuar a execução das metas por ele propostas e salvar a industrialização brasileira de uma crise estrutural gestada ao longo do seu governo. Isso contribuiu na derrota do Marechal Lott, candidato à Presidência da República pela coligação governista PTB/PSD, que elegera JK em 1955, para Jânio Quadros nas eleições de 1960.

\section{Conclusão}

Diante da exposição realizada, bem como de suas múltiplas possibilidades de interpretação sobre o padrão de intervenção estatal no processo de industrialização brasileira, este artigo buscou aprofundar os estudos acerca do planejamento econômico no Brasil no período correspondente ao Plano de Metas (1956-1961). Uma análise dessa dimensão permitiu compreender a atuação do Estado nessa fase, assim como vislumbrar, ainda que de forma incipiente, o conjunto de interesses que nortearam as suas ações na realização dessa estratégia de desenvolvimento, cuja principal prioridade foi implantar a indústria pesada no Brasil.

O Plano de Metas representou, de fato, a estratégia de desenvolvimento mais sólida colocada em prática na história da economia brasileira em prol da industrialização, haja vista o desempenho alcançado pela indústria do país no período, como comprovado nos índices de crescimento alcançados e apresentados. Esse salto industrial, no entanto, só ocorreu com a participação do capital estrangeiro que, ao ingressar na economia brasileira, principalmente na forma de investimento direto, imprimiu-lhe um movimento orientado pelos seus interesses particulares, pois permitiu que filiais de empresas multinacionais dinamizassem a execução das metas setoriais prioritárias do plano conforme os seus desígnios.

Em contrapartida, a economia brasileira acumulou ao longo desse período sucessivos déficits no balanço de pagamentos, altas taxas de inflação, entre outros problemas internos que geraram a desaceleração cíclica da indústria brasileira iniciada no fim da década de 1950. Essa desaceleração marcou o fim do Plano de Metas, de forma a inserir a economia brasileira no início da década de 1960 em uma conjuntura de crise.

Ainda assim, não se pode negar a importância do Plano de Metas enquanto primeira experiência da economia brasileira com o planejamento econômico. Tanto organismos internos quanto os instrumentos criados pelo Estado naquela época para colocar essa estratégia de desenvolvimento em

Página 55 Caderno de Ciências Sociais Aplicadas, Vitória da Conquista/BA, vol. 16, n 27, ano 16, p. 39-57, jan/jun 2019. 
prática puderam ser utilizados pelo país em outros planos de desenvolvimento elaborados posteriormente.

\section{Referências}

BENEVIDES, M. V. M. O Governo Kubitschek: desenvolvimento econômico e político (1956-1961). 3.ed. Rio de Janeiro: Paz e Terra, 1976.

BRASIL. Presidência da República. Conselho do Desenvolvimento. Programa de Metas. Rio de Janeiro, 1958.

CAMPOS, F. A. Estratégias de Desenvolvimento Nacional: o papel do capital estrangeiro entre o segundo Governo Vargas e o Governo Castelo Branco (1951-1966). 2003. Dissertação (Mestrado) - Instituto de Economia Universidade Estadual de Campinas, Campinas, 2003.

CAMPOS, F.A. A arte da conquista: o capital internacional no desenvolvimento capitalista brasileiro (19512002). 2009. Tese (doutorado) - Instituto de Economia, Universidade Estadual de Campinas, Campinas, 2009.

CARDOSO, M.L. Ideologia do desenvolvimento. Brasil: JK/ JQ. Rio de Janeiro: Paz e Terra, 1978.

DIAS, J.L. O BNDE e o Plano de Metas - 1956/61. Rio de Janeiro; FGV - CPDOC, 1996.

DREIFUSS, R. A Internacional capitalista: estratégia e táticas do empresariado transnacional (1918-1986). Rio de Janeiro: Editora Espaço e Tempo, 1986.

FARO, C.; QUADROS, S. A década de 50 e o programa de metas. In: GOMES, Angela (ed.). O Brasil de JK. Rio de Janeiro: Editora da FGV- CPDOC, 1991.

RÜCKERT, I. N. Alguns aspectos das empresas estatais no Brasil. In: Revista Ensaios FEE. V.2, n.1, p. 75-93, 1981.

LAFER, C. O Programa de Metas (1956-1961) - Processo de Planejamento e Sistema Político no Brasil. Rio de Janeiro: Editora FGV, 2002.

LEOPOLDI, Maria Antonieta P. Crescendo em meio à incertę̧a: a política econômica do Governo JK. In: (Org.)

GOMES, A. C. O Brasil de JK. Rio de Janeiro: Fundação Getúlio Vargas/ CPDOC, 1991.

LESSA, C. Quinze anos de política econômica. 4.ed. São Paulo: Brasiliense, 1983

LIMA, H.F. Instrução 113 e "Royalties”. Revista Brasiliense. São Paulo, no 16, mar./abr.. 1958.

MELLO E SOUZA, N. O planejamento econômico no Brasil: considerações críticas. Revista de Administração Pública - RAP [On-line], n. 46, 1968.

OLIVEIRA, J. K. Diretrizes gerais do Plano Nacional de Desenvolvimento. Oscar Nicolau, Belo Horizonte MG, 1955.

Página 56 Caderno de Ciências Sociais Aplicadas, Vitória da Conquista/BA, vol. 16, n 27, ano 16, p. 39-57, jan/jun 2019. 


\section{Cadernos de Ciências SOCIAIS APLICADAS}

OLIVEIRA, JK. A Marcha para o Amanhecer. São Paulo: Bestseller - Importadora de Livros S.A, 1962.

SERRA, J. Ciclos e mudanças estruturais na economia brasileira do pós-guerra. In: (Orgs.) BELLUZZO, L. G. M. e COUTINHO, R. Desenvolvimento capitalista no Brasil: ensaios sobre a crise. 4.ed. Campinas: Unicamp-IE, 1998.

SOCHACZEWSKI, A.C. Desenvolvimento econômico e financeiro no Brasil: 1952-1968. São Paulo: Trajetória Cultural, 1993.

TIRONI, L.F. Politica Econômica e Desenvolvimento Tecnológico - Diversificação ou Especialização no setor de bens de capital sob encomenda. Dissertação (Mestrado) - Instituto de Filosofia e Ciências Humanas Universidade Estadual de Campinas (UNICAMP), 1979.

Recebido em 03 de dezembro de 2018 Aprovado em 05 de abril de 2019

Página 57 Caderno de Ciências Sociais Aplicadas, Vitória da Conquista/BA, vol. 16, n 27, ano 16, p. 39-57, jan/jun 2019. 